ORIGINAL ARTICLE

\title{
The effect of statins versus untreated dyslipidaemia on renal function in patients with coronary heart disease. A subgroup analysis of the Greek atorvastatin and coronary heart disease evaluation (GREACE) study
}

\author{
V G Athyros, D P Mikhailidis, A A Papageorgiou, A N Symeonidis, A N Pehlivanidis, \\ V I Bouloukos, M Elisaf
}

J Clin Pathol 2004;57:728-734. doi: 10.1136/icp.2003.012989

Background: Little is known about statins in the prevention of dyslipidaemia induced renal function decline. The secondary coronary heart disease (CHD) prevention GREACE study suggested that dose titration with atorvastatin (10-80 mg/day, mean dose $24 \mathrm{mg} /$ day) achieves the national cholesterol educational programme treatment goals and significantly reduces morbidity and mortality, compared with usual care.

Aims: To report the effect of statin on renal function compared with untreated dyslipidaemia in both treatment groups.

Methods/Results: All patients had plasma creatinine values within the reference range $<115 \mu \mathrm{mol} /$ litre (13 mg/litre). The on study creatinine clearance $(\mathrm{CrCl})$, as estimated (for up to 48 months) by the Cockroft-

See end of article for authors' affiliations

Correspondence to: Dr V G Athyros, 15 Marmara St, Thessaloniki, 551 32, Greece; athyros@ med.auth.gr

Accepted for publication 21 October 2003 Gault formula, was compared within and between treatment groups using analysis of variance to assess differences over time. Patients from both groups not treated with statins (704) showed a $5.2 \%$ decrease in $\mathrm{CrCl}(\mathrm{p}<0.0001)$. Usual care patients on various statins (97) had a $4.9 \%$ increase in $\mathrm{CrCl}$ ( $p=0.003$ ). Structured care patients on atorvastatin (783) had a $12 \%$ increase in $\mathrm{CrCl}$ ( $p<0.0001$ ). This effect was more prominent in the lower two quartiles of baseline $\mathrm{CrCl}$ and with higher atorvastatin doses. After adjustment for 25 predictors of all CHD related events, multivariate analysis revealed a hazards ratio of 0.84 (confidence interval 0.73 to $0.95 ; \mathrm{p}=0.003$ ) with every $5 \%$ increase in $\mathrm{CrCl}$.

Conclusions: In untreated dyslipidaemic patients with $\mathrm{CHD}$ and normal renal function at baseline, $\mathrm{CrCl}$ declines over a period of three years. Statin treatment prevents this decline and significantly improves renal function, potentially offsetting an additional factor associated with CHD risk. h has been reported recently that of 4483 apparently healthy men participating in the physicians' health study with an initial serum creatinine (SCr) $<115 \mu \mathrm{mol} /$ litre ( $13 \mathrm{mg} /$ litre), those with low high density lipoprotein (HDL) cholesterol and high non-HDL cholesterol had double the risk of renal insufficiency, during longterm follow up, after adjusting for other risk factors. ${ }^{1}$ Although studies in animal models have found a favourable effect of lipid reduction on the progression of renal disease, ${ }^{2-4}$ the results of trials in humans are less clear, because most controlled trials have been too small to make a definitive conclusion. ${ }^{5}$ The Helsinki heart study, ${ }^{6}$ a primary prevention trial, was the first survival study with hypolipidaemic drug treatment to address the issue. Authors reported that dyslipidaemia increased SCr values in patients with normal baseline renal function, both in the placebo and gemfibrozil subgroups, suggesting that treatment with a fibrate could not prevent the deterioration of renal function. Fibrates may increase SCr concentrations, although gemfibrozil, which was used in the Helsinki heart study, usually does not exert this adverse effect. ${ }^{7}$

\begin{abstract}
"Although studies in animal models have found a favourable effect of lipid reduction on the progression of renal disease, the results of trials in humans are less clear, because most controlled trials have been too small to make a definitive conclusion"
\end{abstract}

The recently published MRC/BHF heart protection study (HPS) subgroup analysis for participants with diabetes mellitus $^{8}$ showed that unadjusted SCr concentrations increased in all patients, with or without diabetes mellitus, over a period of 4.6 years. However, allocation to simvastatin (40 mg/day) significantly decreased the rise in SCr values in patients with and without diabetes mellitus. ${ }^{8}$

The Greek atorvastatin and coronary heart disease evaluation (GREACE) study, ${ }^{10}$ a prospective, randomised, target based, open label secondary coronary heart disease (CHD) prevention trial, suggested that structured management of dyslipidaemia with dose titration of atorvastatin can achieve the national cholesterol educational programme (NCEP) treatment goals ${ }^{11} 12$ and provide significant reductions in morbidity and mortality, in comparison with usual care. In the present subgroup analysis of the GREACE results, we report the longterm effect of structured versus usual care (intention to treat analysis), and the effect of statin versus no hypolipidaemic drug treatment (treatment based analysis) on estimated creatinine clearance $(\mathrm{CrCl})$.

\footnotetext{
Abbreviations: $\mathrm{ACE}$, angiotensin converting enzyme; $\mathrm{C}$, cholesterol; $\mathrm{CHD}$, coronary heart disease; $\mathrm{Cl}$, confidence interval; $\mathrm{CrCl}$, creatinine clearance; GFR, glomerular filtration rate; GREACE, Greek atorvastatin and coronary heart disease evaluation; $\mathrm{HDL}$, high density lipoprotein; HPS, heart protection study; HR, hazard ratio; K/DOQI, kidney disease outcomes and quality initiative; LDL, low density lipoprotein; NCEP, national cholesterol educational programme; SCr, serum creatinine; TG, triglyceride
} 


\section{METHODS}

\section{Study design, patients, and methods}

The design of the GREACE study and the findings on mortality, morbidity, cost effectiveness, and longterm safety have been described previously. ${ }^{13}$ In brief, the patients were men $(78 \%)$ and women (22\%) with established CHD, aged $<75$ years old (mean, 58.3). Their serum low density lipoprotein cholesterol (LDL-C) and serum triglyceride (TG) concentrations had to be $>2.6 \mathrm{mmol} /$ litre $(1000 \mathrm{mg} /$ litre $)$ and $<4.5 \mathrm{mmol} /$ litre (4000 $\mathrm{mg} /$ litre), respectively. Patients with recent acute coronary syndromes were not excluded. The study received local ethical approval and informed consent was obtained from all patients before enrolment. All patients attended the atherosclerosis unit of the University Hospital, Thessaloniki, Greece, and if eligible were randomised either into the structured care group, followed up by the university clinic, or into the usual care group, followed up by heart specialists or general practitioners of the patient's choice outside the hospital. In the structured care group, the starting dose of atorvastatin was $10 \mathrm{mg}$ /day. With evaluations every six weeks, the dose of atorvastatin was titrated up to $80 \mathrm{mg} /$ day for patients not reaching the NCEP LDL-C goal $(<2.6 \mathrm{mmol} /$ litre; $1000 \mathrm{mg} /$ litre $)$ with lower dosages. Patients in the usual care group were treated according to their physician's standard of care. Usual care included life style changes, such as low fat diet, weight loss, and exercise, in addition to all necessary drug treatment and lipid lowering agents. Atorvastatin was not excluded from the usual care group. After dose titration, patients were followed for a mean three year period, with visits every six months. SCr was measured using the Jaffé method (Olympus Diagnostica $\mathrm{GmbH}$; Clare, Ireland) and the normal range was 55$115 \mu \mathrm{mol} /$ litre (6-13 mg/litre). $\mathrm{CrCl}$ was estimated from the SCr values by the Cockroft-Gault formula. This formula includes factors that correct for age, weight, and sex. ${ }^{14}$

\section{Endpoints}

Primary endpoints were all cause and coronary mortality, coronary morbidity (non-fatal myocardial infarction, revascularisation, unstable angina, and congestive heart failure), and stroke. Moreover, the composite endpoint "all vascular events" comprising all primary endpoints (all coronary events plus stroke) was used. Secondary endpoints were safety and efficacy of longterm atorvastatin treatment, cost effectiveness of structured care, and the assessment of the relation between CHD risk factors and clinical outcomes. The present analysis based on $\mathrm{SCr}$ is post hoc.

\section{Statistical analyses}

Both intention to treat and treatment based analyses of all patients randomised to the structured or usual care groups were performed. $\mathrm{CrCl}$ was assessed at baseline, at the sixth treatment week, and every six months thereafter. On study $\mathrm{CrCl}$ values were compared with those at baseline, using analysis of variance (ANOVA) to assess differences over time within and between treatment groups. A univariate analysis was performed initially, including 25 predictors of CHD related events. Then, after removal of six predictors with a $\mathrm{p}>0.10,19$ predictors were included in a multivariate Cox predictive model, involving backward stepwise logistic regression, for all CHD related events. All predictors were recorded as categorical factors (0-1), except for $\mathrm{CrCl}$, which was analysed as a continuous parameter. All univariate or multivariate analyses were performed with a 5\% stepwise increase or reduction of $\mathrm{CrCl}$ from baseline. A two tailed value of $\mathrm{p}<0.05$ was considered significant. The Statgraphics Plus (Statgraphics, Rockville, Maryland, USA) program was used for all forms of statistical analysis.
RESULTS

\section{Hypolipidaemic drug treatment and its effect on the} lipid profile

Details of these findings have been published previously. ${ }^{9}$ Briefly, in the structured care group all patients $(\mathrm{n}=800)$ received atorvastatin. After dose titration, the patients on atorvastatin received the following dosages: $4 \%$ (31 patients), $10 \mathrm{mg} /$ day; 82\% (657), $20 \mathrm{mg} /$ day; $11 \%$ (87), $40 \mathrm{mg} /$ day; and $3 \%$ (25), $80 \mathrm{mg} /$ day. The mean dose was $24 \mathrm{mg} /$ day. During the study, 17 patients on atorvastatin dropped out because of side effects or personal reasons. In the structured care group, $95 \%$ of patients $(\mathrm{n}=759)$ had mean LDL-C values $<2.6 \mathrm{mmol} /$ litre ( $1000 \mathrm{mg} / \mathrm{litre})$ after the titration period (mean change, $-46 \%$ ). The mean reduction in TGs was $31 \%$, and in non-HDL-C 44\% $(\mathrm{p}<0.0001 v$ baseline and on study values of usual care for both). The mean increase in HDL-C was $7 \%(p<0.001 v$ baseline and $\mathrm{p}=0.028 v$ on study values of the usual care group). The LDL-C to HDL-C ratio was reduced by $50 \%(\mathrm{p}<0.0001 v$ baseline and usual care). In the usual care group, only $26 \%(\mathrm{n}=211)$ of the patients received hypolipidaemic drug treatment. Some patients ( $\mathrm{n}=98 ; 12 \%)$ discontinued these drugs after a six to eight month period. Thus, only a small proportion of the usual care patients received longterm hypolipidaemic drug treatment $(14 \% ; n=113)$, mainly with statins $(12 \%$; $n=97)$ or fibrates $(2 \% ; n=16)$. Only $3 \%$ of usual care patients $(\mathrm{n}=24)$ attained the NCEP LDL-C treatment goal.

\section{Endpoints}

During the three year duration of the study, 292 CHD related events were recorded in 1600 patients: 196 (24.5\%) patients on usual care had a CHD recurrent event or died compared with $96(12 \%)$ patients on atorvastatin (risk ratio, 0.49; confidence interval (CI), 0.27 to $0.73 ; \mathrm{p}<0.0001) .{ }^{9}$ In detail, compared with usual care, structured care reduced total mortality by $43 \%(p=0.0021)$, coronary mortality by $47 \%$ $(\mathrm{p}=0.0017)$, coronary morbidity by $54 \%(\mathrm{p}<0.0001)$, and stroke by $47 \%(\mathrm{p}=0.034)$.

\section{Renal function at baseline}

In the kidney disease outcomes and quality initiative (K/ DOQI) guidelines, ${ }^{15}$ chronic kidney disease is defined according to the presence or absence of kidney damage and degree of kidney function, irrespective of diagnosis. Among individuals with chronic kidney disease, five stages are described based on the degree of function indicated by glomerular filtration rate (GFR). In this classification scheme, stage one is associated with kidney damage with a normal GFR $(\geqslant 90 \mathrm{ml} / \mathrm{min})$, stage two with kidney damage and mildly decreased GFR (60-89 ml/min), stage three with moderately decreased GFR (30-59 ml/min), stage four with severely decreased GFR (15-29 $\mathrm{ml} / \mathrm{min})$, and stage five or kidney failure with a GFR less than 15. According to K/DOQI, 642 patients had a stage one, 864 a stage two, and 94 a stage three renal function status. Patients from each renal function status were similarly distributed in the two treatment groups.

\section{Effect of dyslipidaemia and statin treatment on $\mathrm{CrCl}$ (treatment based analysis) \\ No statin treatment}

In the usual care group, 687 patients were not on longterm hypolipidaemic drug treatment. These patients showed a mean reduction in $\mathrm{CrCl}$ of $5.3 \%(\mathrm{p}<0.0001$; table 1 ; fig 1 ). At baseline, there were no significant differences in CHD risk factors between these patients and those in the structured care group on atorvastatin. Similarly, 17 patients in the structured care group who discontinued atorvastatin, for various reasons, had a decrease in $\mathrm{CrCl}$ of $4.9 \%(\mathrm{p}=0.02$; table $\mathrm{l}$; fig 1). 
Table 1 Creatinine clearance in the two treatment groups at baseline and at 48 months according to hypolipidaemic drug treatment (treatment based analysis)

\begin{tabular}{llll}
\hline & Baseline & 48th month & p Value \\
\hline Usual care, no statins $(n=703)$ & $77(10)$ & $72(12)-5.3 \%$ & $<0.0001$ \\
Usual care, on statins $(n=97)$ & $78(12)$ & $82(8)+4.9 \%$ & 0.003 \\
Structured care, no atorvastatin $(n=17)$ & $76(9)$ & $73(9)-4.9 \%$ & 0.02 \\
Structured care, on atorvastatin $(n=783)$ & $76(13)$ & $84(3)+12 \%$ & $<0.0001$ \\
\hline Values are mean (SD) in $\mathrm{ml} / \mathrm{min}$. & & & \\
\hline
\end{tabular}

Statin treatment

In the usual care group, simvastatin was used in 41 patients (5\%; mean dose, $20 \mathrm{mg} /$ day) and induced a mean $5.2 \%$ increase in $\mathrm{CrCl}(\mathrm{p}=0.002)$; atorvastatin was used in 25 patients (3\%, mean dose, $15 \mathrm{mg} /$ day) and increased $\mathrm{CrCl}$ by $8.1 \%(\mathrm{p}=0.0003)$; pravastatin was used in 23 patients $(3 \%$; mean dose, $24 \mathrm{mg} /$ day) and fluvastatin in eight patients (1\%; mean dose, $40 \mathrm{mg} /$ day), with no significant increases in $\mathrm{CrCl}$ (2.4\% and $1.8 \%$, respectively). The overall effect on $\mathrm{CrCl}$ in statin treated patients $(\mathrm{n}=96)$ was a $5 \%$ increase in $\mathrm{CrCl}$ $(\mathrm{p}=0.003$; table $\mathrm{l}$; fig $\mathrm{l})$. In the structured care group, 783 patients were on longterm atorvastatin treatment (mean dose, $24 \mathrm{mg} /$ day) and showed a mean increase in $\mathrm{CrCl}$ of $12 \%$ $(\mathrm{p}<0.0001$; table 1 ; fig 1$)$. This increase was dependent on baseline $\mathrm{CrCl}$ values. Figure 2 shows the increase in $\mathrm{CrCl}$ by baseline $\mathrm{CrCl}$ quartiles (intention to treat analysis). Patients with a GFR $<77 \mathrm{ml} / \mathrm{min}$ had a mean increase in $\mathrm{CrCl}$ of $15.4 \%$, whereas those with a GFR $>77 \mathrm{ml} / \mathrm{min}$ had a mean increase in $\mathrm{CrCl}$ of $3.1 \%$. Thus, the greatest benefit was seen in those with early renal dysfunction. Patients on higher atorvastatin doses (40-80 mg/day; $\mathrm{n}=112$ ) showed a greater increase in $\mathrm{CrCl}$ than those on lower doses $(10-20 \mathrm{mg} /$ day; $\mathrm{n}=688): 13.8 \% \quad v \quad 10.9 \%$, respectively $(\mathrm{p}=0.001)$. In multivariate analysis, statin treatment showed a hazards ratio (HR) of 0.51 ( $95 \%$ CI, 0.39 to 0.66 ; $\mathrm{p}<0.0001 ;$ table 2).

\section{Changes in $\mathrm{CrCl}$ values in the structured and usual care groups (intention to treat analysis)}

The following $\mathrm{CrCl}$ values were recorded in the two treatment groups at baseline and during the study.

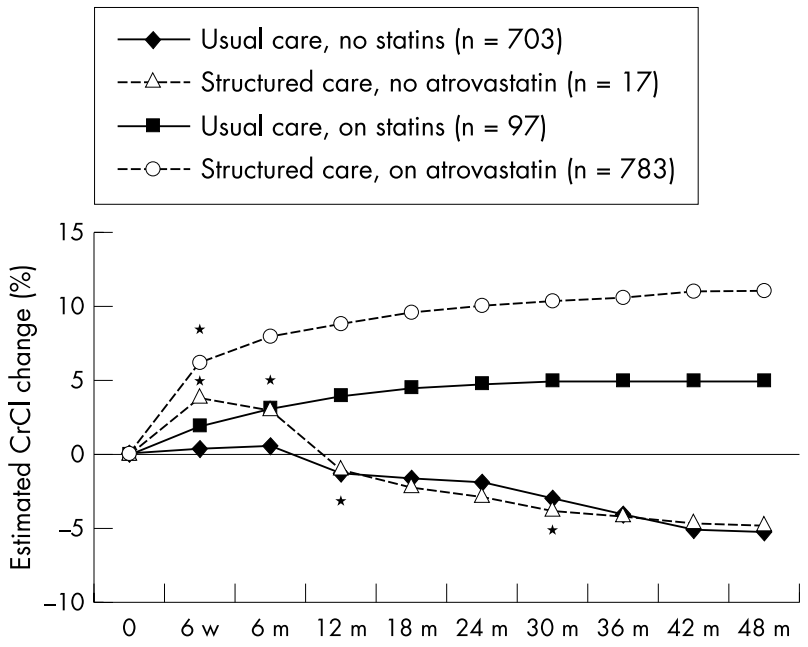

Figure 1 Percentage change over time (up to 48 months) in creatinine clearance $(\mathrm{CrCl})$ in the structured and usual care groups, according to hypolipidaemic drug treatment (treatment based analysis). m, months; $w$, weeks; ${ }^{*}$ time at which the difference became significant $(p<0.05)$ compared with baseline.

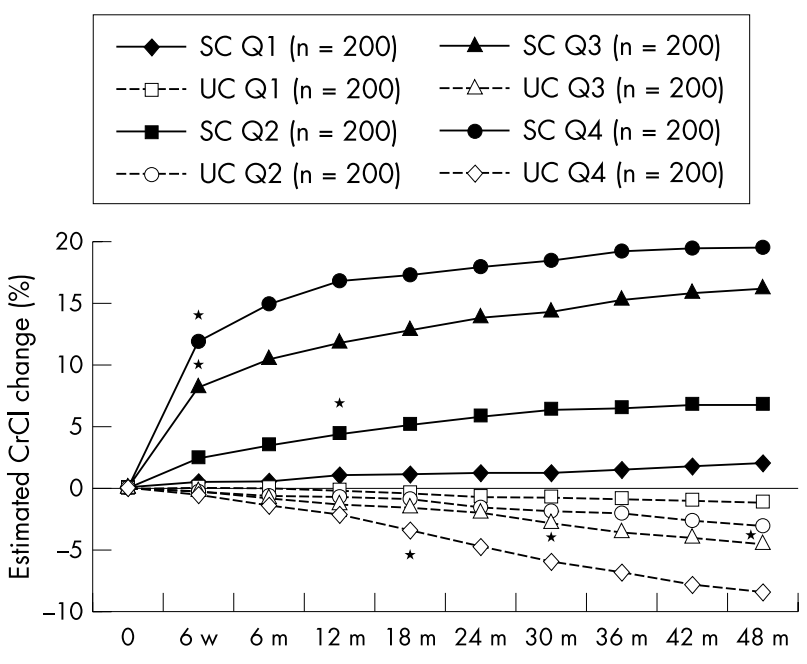

Figure 2 Percentage change over time (up to 48 months) in creatinine clearance $(\mathrm{CrCl})$ in the structured and usual care groups, by baseline $\mathrm{CrCl}$ quartiles (intention to treat analysis). m, month; $\mathrm{Q}$, quartile; Q1, highest Q; Q4, lowest Q; SC, structured care; UC, usual care; w, week; *time at which difference became significant $(p<0.05)$ compared with baseline.

Table 2 Multivariate Cox predictive model for all CHD related events involving backward stepwise logistic regression

\begin{tabular}{|c|c|c|}
\hline \multirow[b]{2}{*}{ Variables } & \multicolumn{2}{|c|}{$\begin{array}{l}\text { Multivariate Cox predictive model } \\
\text { for all CHD related events }\end{array}$} \\
\hline & $\operatorname{HR}(95 \% \mathrm{Cl})$ & p Value \\
\hline Age (years) & $1.07(1.02$ to 1.11$)$ & 0.02 \\
\hline Statin treatment & 0.51 (0.39 to 0.66$)$ & $<0.0001$ \\
\hline $\begin{array}{l}\text { On treatment LDL-C } \\
<2.6 \mathrm{mmol} / /\end{array}$ & 0.67 (0.49 to 0.84$)$ & $<0.0001$ \\
\hline $\begin{array}{l}\text { On treatment LDL-C } \\
>3.6 \mathrm{mmol} / /\end{array}$ & 1.32 (1.13 to 1.56$)$ & $<0.0001$ \\
\hline $\begin{array}{l}\text { On treatment } \mathrm{HDL}-\mathrm{C} \\
>1.0 \mathrm{mmol} / \mathrm{l}\end{array}$ & $0.87(0.79$ to 0.94$)$ & 0.002 \\
\hline $\begin{array}{l}\text { On treatment } \mathrm{HDL}-\mathrm{C} \\
<1.0 \mathrm{mmol} / \mathrm{l}\end{array}$ & 1.12 (1.04 to 1.28$)$ & 0.005 \\
\hline $\mathrm{CrCl}$ (with every $5 \%$ increase) & $0.84(0.73$ to 0.95$)$ & 0.003 \\
\hline $\mathrm{CrCl}$ (with every $5 \%$ reduction) & $1.10(1.03$ to 1.21$)$ & 0.01 \\
\hline Use of $\beta$ blockers during study & $0.72(0.58$ to 0.89$)$ & $<0.0001$ \\
\hline $\begin{array}{l}\text { Use of ACE inhibitors during } \\
\text { study }\end{array}$ & $0.84(0.69$ to 0.96$)$ & 0.01 \\
\hline \multicolumn{3}{|c|}{$\begin{array}{l}\text { Nineteen univariate predictors of all CHD related events all with } \mathrm{p}<0.10 \\
\text { (the above plus: male sex, female sex, current smoking, family history of } \\
\text { premature CAD, history of hypertension, history of diabetes mellitus, } \\
\text { previous revascularisation, acute coronary syndrome, and previous } \\
\text { myocardial infarction) were initially entered ( } n=1600,292 \text { events). } \\
\text { ACE, angiotensin converting enzyme; } \mathrm{CAD} \text {, coronary artery disease; } \\
\mathrm{CHD} \text {, coronary heart disease; } \mathrm{Cl} \text {, confidence interval; } \mathrm{CrCl} \text {, creatinine } \\
\text { clearance; } \mathrm{HDL}-\mathrm{C} \text {, high density lipoprotein cholesterol; } \mathrm{HR} \text {, hazards ratio; } \\
\mathrm{LDL}-\mathrm{C} \text {, low density lipoprotein cholesterol. }\end{array}$} \\
\hline
\end{tabular}


Table 3 Creatinine clearance values in the two treatment groups at baseline and at 48 months (intention to treat analysis)

\begin{tabular}{|c|c|c|c|c|c|c|}
\hline & \multicolumn{3}{|c|}{ Structured care $(n=800)$} & \multicolumn{3}{|c|}{ Usual care $(n=800)$} \\
\hline & Baseline & 48th month & $\mathrm{p}$ Value & Baseline & 48th month & p Value \\
\hline Q1 $(n=200)$ & $95(11)$ & 96 (13) & NS & $96(10)$ & $95(10)$ & NS \\
\hline Q2 $(n=200)$ & $77(3)$ & $80(5)$ & 0.002 & $78(4)$ & $76(5)$ & 0.03 \\
\hline Q3 $(n=200)$ & $70(2)$ & $80(3)$ & $<0.0001$ & $70(3)$ & $67(4)$ & 0.002 \\
\hline Q4 $(n=200)$ & $61(4)$ & $74(6)$ & $<0.0001$ & $63(5)$ & $59(6)$ & $<0.0001$ \\
\hline All $(n=800)$ & 76 (13) & $84(8)$ & $<0.0001$ & 77 (12) & $74(11)$ & 0.008 \\
\hline
\end{tabular}

Values are mean (SD) in $\mathrm{ml} / \mathrm{min}$.

$Q$, quartile.

Usual care group

The mean (SD) baseline CrCl was 77 (12) $\mathrm{ml} / \mathrm{min}$ and this was reduced by the end of the study to 74 (11) $\mathrm{ml} / \mathrm{min}(4.4 \%$; $\mathrm{p}=0.002$ ). Table 3 and fig 2 show the $\mathrm{CrCl}$ values by quartiles and their changes during the study are reported.

\section{Structured care group}

The mean (SD) baseline $\mathrm{CrCl}$ was 76 (13) $\mu \mathrm{mol} / \mathrm{litre}$. This was increased by the end of the study to 84 (8) $\mu \mathrm{mol} / \mathrm{litre}$ (11.6\%; $\mathrm{p}<0.0001$ ). Table 3 and fig 2 show the $\mathrm{CrCl}$ values by quartiles and their changes during the study.

\section{Relation between $\mathrm{CrCl}$ values and clinical outcome}

In all patients, multivariate analysis of CHD related events revealed an HR of 1.10 (95\% CI, 1.03 to 1.21 ; p $=0.01$ ) with each 5\% reduction in $\mathrm{CrCl}$ (table 2 ) and an $\mathrm{HR} 1.18$ (95\% CI, 1.09 to $1.29 ; \mathrm{p}<0.001$ ) with each $10 \%$ reduction in $\mathrm{CrCl}$. In contrast, multivariate analysis of $\mathrm{CHD}$ related events revealed an HR of 0.84 (95\% CI, 0.73 to $0.95 ; \mathrm{p}=0.003$ ) with each $5 \%$ increase in $\mathrm{CrCl}$ (table 2) and an $\mathrm{HR}$ of 0.73 (95\% CI, 0.64 to $0.82 ; \mathrm{p}<0.001$ ) with each $10 \%$ increase in $\mathrm{CrCl}$.

\section{The role of blood pressure and HDL-C}

Both systolic blood pressure and diastolic blood pressure were similar at baseline and during the study in the structured and usual care patients, and among all quartiles of baseline $\mathrm{CrCl}$ in both treatment groups (table 4). The effect of statin treatment on blood pressure could not be assessed because patients were also on other blood pressure lowering drugs ( $\beta$ blockers, angiotensin converting enzyme (ACE) inhibitors, calcium channel blockers, diuretics, and nitrates). ${ }^{9}$ There were no significant differences in LDL-C and TG values between the $\mathrm{CrCl}$ quartiles. There was a lower HDL-C mean value in the low baseline $\mathrm{CrCl}$ quartiles of both the structured (ANOVA, $p=0.002$ ) and usual care groups (ANOVA, $\mathrm{p}=0.0001$ ). These differences remained significant during the study in the usual care group, but significance was abolished in the structured care group.

\section{Other factors that may have influenced clinical outcome}

There were no significant differences between the structured and usual care groups in demographic characteristics and CHD factors at baseline and in concomitant drug treatment (particularly in ACE inhibitors or calcium channel blockers, which might influence GFR; table 5) and degree of glycaemic control or blood pressure during the study. ${ }^{9}$ Both at entry and during the study, smokers were similarly distributed in the two treatment groups $(4.5 \%$ and $3.6 \%$ in the usual care and structured care groups, respectively). Only five patients in the usual care group and three in the structured care group were on a low protein diet. Similar numbers of patients lost $>10 \%$ of their body weight in the two treatment groups (39 in the usual care and 45 in the structured care groups). Nevertheless, every measurement of SCr was adjusted for body weight and the Cockroft-Gault formula, used to calculate GFR from SCr, corrects for age, sex, and body weight. Thus, it is not possible that we had false low or false high GFR values. Moreover, results were fully adjusted for 26 predictors of CHD related events (table 3 ). Thus, the beneficial effect on clinical outcome should mainly be attributable to statin treatment. There were no extreme values of $\mathrm{SCr}$ at baseline (that is, extremely high values) because the patients were excluded from the study if they had a SCr value $>13 \mathrm{mg} /$ litre; $115 \mu \mathrm{mol} /$ litre. The method used to assess SCr has high reproducibility, and the use of mean values of a large number of patients (800 in each treatment group), together with the different effects on SCr in each group, reduced to a minimum any regression to the mean effect. All patients in both treatment groups received advice on life style changes and the body mass index (a rough index of compliance with life style measures) was similar in both groups. ${ }^{9}$

\section{DISCUSSION}

The present study suggests that renal function declines, as shown by the significant decrease in $\mathrm{CrCl}$ values, over a period of three years in dyslipidaemic patients with CHD and normal renal function at baseline who are not treated with a statin. Moreover, statin treatment not only inhibits this deterioration in renal function, but it significantly increases $\mathrm{CrCl}$ in these patients. The greatest benefit is seen in those with early renal dysfunction.

In the Helsinki heart study, ${ }^{6}$ there was an average 3\% increase in SCr during the five year period of the study (both in the placebo and gemfibrozil subgroups). This was a primary prevention study, and therefore the decline of renal function may have been slower. Dyslipidaemia and hypertension accelerated this change. ${ }^{6}$ Subjects with an LDL-C to HDL-C ratio $>4.4$ had a $20 \%$ faster decline than those with a ratio $<3.2$. Both the contribution of the lipoprotein ratio and the protective effect of HDL-C alone remained significant in multiple regression analyses. Our patients had a mean LDL-C to HDL-C ratio value of 4.6 , which was reduced by $50 \%$ (to $2.3)$, HDL-C was increased by $7 \%$ with atorvastatin, and $40 \%$ of patients had arterial hypertension, which was also effectively treated in most of the patients. ${ }^{9}$ Thus, effective treatment of two risk factors for renal function deterioration might explain the reduction in $\mathrm{SCr}$ and the consequent $\mathrm{CrCl}$ increase. Nevertheless, efficient treatment of hypertension over a three year period could explain the stabilisation of the $\mathrm{CrCl}$ values, but probably not its significant increase. This interpretation is supported by several findings of the study. First, 17 patients from the structured care group who discontinued atorvastatin, for various reasons, and those on usual care not on statins $(\mathrm{n}=687)$ had a significant reduction (compared with baseline ) in $\mathrm{CrCl}$ of $4.9 \%$ and $5.3 \%$, respectively, by the end of the study (fig 1), despite having similar systolic and diastolic blood pressure values to those of statin treated patients (table 4). Second, the $\mathrm{CrCl}$ increase was seen 
Table 4 SBP and DBP in both treatment groups at baseline and during treatment of baseline quartiles of creatinine clearance values

\begin{tabular}{|c|c|c|c|c|c|}
\hline & Q1 & Q2 & Q3 & Q4 & ANOVA \\
\hline \multicolumn{6}{|c|}{ Structured care $(n=800)$} \\
\hline Baseline SBP & $124(17)$ & $122(14)$ & $123(16)$ & $125(16)$ & NS \\
\hline On study SBP & $123(13)$ & $122(12)$ & $121(11)$ & $123(13)$ & NS \\
\hline $\mathrm{p}$ Value & NS & NS & NS & NS & \\
\hline Baseline DBP & $76(10)$ & $74(8)$ & $75(9)$ & $75(9)$ & NS \\
\hline On study DBP & 75 (7) & $74(8)$ & $74(7)$ & $73(8)$ & NS \\
\hline $\mathrm{p}$ Value & NS & NS & NS & NS & \\
\hline \multicolumn{6}{|c|}{ Usual care $(n=800)$} \\
\hline Baseline SBP & $122(15)$ & $120(16)$ & $124(14)$ & $123(15)$ & NS \\
\hline On study SBP & $120(14)$ & $122(14)$ & 123 (13) & $122(11)$ & NS \\
\hline p Value & NS & NS & NS & NS & \\
\hline Baseline DBP & $75(8)$ & $76(9)$ & $75(9)$ & $73(10)$ & NS \\
\hline On study DBP & $75(8)$ & $75(7)$ & $76(9)$ & $72(8)$ & NS \\
\hline p Value & NS & NS & NS & NS & \\
\hline
\end{tabular}

in structured care patients with low baseline $\mathrm{CrCl}$ (fig 2), despite the fact that they had similar systolic and diastolic blood pressure values to those with a high baseline $\mathrm{CrCl}$ (tables 2 and 3). Third, the reduction in $\mathrm{CrCl}$ was more prominent in usual care patients with low baseline $\mathrm{CrCl}$ (fig 2), despite the fact that they had similar systolic and diastolic blood pressure values to those with high baseline $\mathrm{CrCl}$ (table 4). Furthermore, it has been shown in the Losartan intervention for endpoint reduction in hypertension $\operatorname{trial}^{16}$ that during the study SCr increased by $13 \%$ in both treatment groups, despite effective control of blood pressure. Moreover, in spontaneously hypertensive rats, statins reduce hypertension related renal damage and proteinuria, independently of cholesterol or blood pressure values. ${ }^{17}$

"The early increase in creatinine clearance in the structured care group is probably related to an effect of statin treatment on endothelial related vasodilatation"

In the structured care group, the lower the baseline $\mathrm{CrCl}$ value (even within the normal range), the greater the poststatin increase (fig 2). Data suggest that this was a direct effect of atorvastatin on renal function, because the increase in $\mathrm{CrCl}$ was manifested as early as the sixth week of treatment. Moreover, in the patients who discontinued atorvastatin treatment (personal reasons or side effects), the $\mathrm{CrCl}$ returned to previous values within four weeks, even though other treatments were continued. The increase in $\mathrm{CrCl}$ values gradually became higher after the sixth week of treatment. There are three possible explanations for this. First, the effect of atorvastatin may be dose dependent. Our results suggest that higher doses of atorvastatin increase $\mathrm{CrCl}$ more than lower doses. By the sixth week of treatment, all patients $(\mathrm{n}=800)$ were on a $10 \mathrm{mg} /$ day dose, whereas after titration most patients $(\mathrm{n}=657)$ were on $20 \mathrm{mg} /$ day, and some $(\mathrm{n}=112)$ were on 40 or $80 \mathrm{mg} /$ day. Second, a gradual improvement of the lipid profile during the titration period, as the atorvastatin doses increased, might be another possible explanation. Third, patients on structured care had fewer CHD recurrent events during the study, thus preserving cardiac performance and renal blood flow.

The early increase in $\mathrm{CrCl}$ in the structured care group is probably related to an effect of statin treatment on endothelial related vasodilatation. It is well known that statins exert a beneficial effect on endothelial vasomotor function. $^{18}{ }^{19}$ In fact, better perfusion of the myocardium and improved coronary blood flow have been documented soon after starting statin treatment. ${ }^{18-21}$ Therefore, better renal blood flow is a possibility. Regression of atheromatous renal artery stenosis, regression of intimal hyperplasia in arcuate arteries, or reversal of hyaline arteriosclerosis in afferent arterioles are unlikely to be achieved as early as the sixth week of treatment. However, such effects might be involved in the further gradual increase of $\mathrm{CrCl}$ during the three year study period. It has also been suggested that dyslipidaemia per se is a significant aggravating factor for renal dysfunction in patients with diabetes ${ }^{22}$ and hypertension ${ }^{6}$; in the GREACE trial, $20 \%$ of our patients had diabetes and $40 \%$ had arterial hypertension. High serum cholesterol seems to have a similar action on glomerular mesangial cells and endothelial cells. ${ }^{22}$ This appears to be analogous to the process of atherosclerosis, because mesangial cells have binding sites for LDL and oxidised LDL, help recruit macrophages, and secrete proliferative factors. Clinical and experimental studies have demonstrated the role of lipids and lipoproteins in the

Table 5 Medical treatment during the study (for at least six months)

\begin{tabular}{|c|c|c|c|c|c|}
\hline & \multicolumn{2}{|c|}{ Structured care $(n=800)$} & \multicolumn{2}{|c|}{ Usual care $(n=800$ ) } & \multirow{2}{*}{$\begin{array}{l}\text { Difference } \\
\text { p Value }\end{array}$} \\
\hline & Patients & Percentage & Patients & Percentage & \\
\hline $\begin{array}{l}\text { Aspirin or other antiplatelet } \\
\text { agents }\end{array}$ & 712 & 89 & 692 & 86 & NS \\
\hline$\beta$ Blockers & 685 & 86 & 674 & 84 & NS \\
\hline ACEI or ARBS & 439 & 55 & 425 & 53 & NS \\
\hline Nitrates & 103 & 13 & 126 & 16 & NS \\
\hline Calcium channel blockers & 206 & 25 & 224 & 28 & NS \\
\hline Diuretics & 89 & 11 & 104 & 13 & NS \\
\hline Hypolipidaemic drugs & 783 & 98 & 113 & 14 & $<0.0001$ \\
\hline
\end{tabular}


decline of renal function, with an emphasis on glomerulosclerosis. ${ }^{23-26}$ Statins have been shown to have a protective effect on renal function, by diminishing the lipid contribution to glomerulosclerosis, ${ }^{27}$ reducing neutrophil and macrophage infiltration, ${ }^{27}$ and upregulating the cytokine interleukin $6^{28} 29$ or endothelial nitric oxide synthase. ${ }^{30}$ In this setting, several animal studies have been reported in which the rate of decline of GFR and/or renal morphology is beneficially modified after the alteration of the lipoprotein profile by dietary or pharmacological manipulation, including statins. ${ }^{2} 3132$ Thus, the possibility that both the pleotropic effects of atorvastatin and the improved lipid profile contributed to this effect cannot be excluded.

It is plausible that the fall in SCr values, as opposed to a decrease in the expected rise seen in the HPS trial, ${ }^{73}$ may only be seen when a considerable reduction in LDL-C is achieved. ${ }^{34}{ }^{35}$ In the GREACE trial, ${ }^{9}$ the mean fall in LDL-C was $2.0 \mathrm{mmol} /$ litre, whereas in the HPS trial ${ }^{33}$ this was only $1.0 \mathrm{mmol} /$ litre. Moreover, the baseline non-HDL-C value, a significant determinant of deterioration of renal function, was very high in the GREACE patients (mean, $5.6 \mathrm{mmol} / \mathrm{litre}$; $\mathrm{SD}, 0.9)$ and this was reduced in the structured care group by $2.4 \mathrm{mmol} /$ litre $(-44 \% ; \mathrm{p}<0.0001) .^{9}$ In the HPS study, the baseline non-HDL-C value was $4.8 \mathrm{mmol} / \mathrm{litre}$ and was reduced by $1.2 \mathrm{mmol} /$ litre by simvastatin. ${ }^{33}$ The baseline HDL-C value, another significant determinant of deterioration of renal function, ${ }^{1}$ was low in both treatment groups of GREACE ( $1.0 \mathrm{mmol} / \mathrm{litre})$. In the structured care group, the HDL-C values were significantly increased to $1.1 \mathrm{mmol} /$ litre $(7 \% ; \mathrm{p}<0.001)$ during the study. This increase was analogous to that reported by the HPS in simvastatin allocated patients. Thus, differences between the effect of statin treatment on renal function in HPS and GREACE could be mainly attributed to the greater reduction in LDL-C and non-HDL-C values seen in GREACE, because the effect of statin treatment on HDL-C concentrations was similar in both studies.

In the usual care group, $12 \%$ of patients were on longterm statin treatment $(n=97)$. Usual care patients on statins also had an increase in $\mathrm{CrCl}$, but to a lesser extent than that seen in structured care patients $(4.9 \%$ v $12 \%$; $p=0.0003)$. There could be several reasons for this difference. The increase in $\mathrm{CrCl}$ might be more evident with certain statins, and/or the doses of other statins were low and their effect on the lipid profile was limited.

We recently reported ${ }^{36}$ that 26 of 115 primary prevention patients who showed a drop in serum urate also had a $3 \%$ reduction $(\mathrm{p}=0.05)$ in $\mathrm{SCr}$ concentrations during short term atorvastatin treatment. In GREACE, there was also a significant reduction in urate in atorvastatin treated patients, which correlated with the decrease in $\mathrm{SCr} \quad(r=0.82$; $\mathrm{p}<0.0001$; data not shown). One fibrate (fenofibrate) can reduce urate concentrations, by reducing its tubular reabsorption. However, all fibrates, with the exception of gemfibrozil, increase serum creatinine values ${ }^{7}$ through mechanisms that have not yet been clarified. It is highly unlikely that the increase in $\mathrm{CrCl}$ in GREACE is associated with intrarenal alterations in tubular function, given that, unlike urate, SCr is not subject to reabsorption in the renal tubules. Increased $\mathrm{SCr}$ excretion is probably mediated through the improvement in $\mathrm{CrCl}$, to which we also attributed the reduction in urate. Thus, statins and fibrates probably have completely different ways of affecting serum creatinine and urate concentrations. In two other studies, ${ }^{37} 38$ involving patients with peripheral arterial disease, atorvastatin $(20 \mathrm{mg} /$ day; $\mathrm{n}=25 ; \mathrm{p}=0.007)$ and simvastatin $(20 \mathrm{mg} /$ day; $\mathrm{n}=103 ; \mathrm{p}=0.007)$ also decreased $\mathrm{SCr}$ by about $3 \%$. In both these studies, ${ }^{37}{ }^{38}$ and in the GREACE trial, ${ }^{9}$ the decrease in SCr was greater in those with baseline SCr values at the higher end of the reference range.
A low $\mathrm{CrCl}$ (and high SCr) could represent a continuous CHD risk factor even within normal limits. Probably "the lower the better" applies to SCr values, as it does to LDL-C and systolic blood pressure. This hypothesis is supported by the findings of a recent observational study. ${ }^{39}$ This study showed that higher SCr concentrations, mostly within the normal range (mean on study quartile values 84, 94, 104, and $120 \mu \mathrm{mol} /$ litre), were a strong and independent predictor of CHD adverse outcomes and stroke after first myocardial infarction, in 2677 patients during a mean follow up period of 3.4 years; most of our patients had suffered a recent myocardial infarction.

\section{"Statins and fibrates probably have completely different ways of affecting serum creatinine and urate concentra- tions"}

There are several limitations to our study. The potential effect of atorvastatin on renal function will need to be investigated extensively using more specific tests (for example, urine collections for $\mathrm{CrCl}$ and the use of isotopes or markers such as inulin or ${ }^{51} \mathrm{Cr}$-EDTA clearance). The GREACE study was not double blind and placebo controlled because of ethical and practical issues. This unsponsored target based study could not be designed in any other way, because its main goal was to assess the clinical benefit from NCEP guideline implementation in comparison with that seen with real life treatment patterns. Only a few patients on statins other than atorvastatin were evaluated. Urine analyses were not performed to assess microalbuminuria, an alternative marker for kidney disease. Proteinuria was assessed at baseline and at the end of the study, and we found no evidence that the statins used in the study induced or exacerbated preexisting proteinuria. In addition, there are no reported cases in the literature showing that atorvastatin induces proteinuria, whereas there are studies suggesting that it reduces it significantly, ${ }^{34}$ even over and above the reduction induced by ACE inhibitors or angiotensin receptor blockers. ${ }^{40}$ Moreover, in the GREACE diabetes substudy, ${ }^{41}$ there was no evidence of an increased risk of developing proteinuria in the safety data of the patients with diabetes on atorvastatin for three years, in accordance with previous observations. ${ }^{42}$ However, this is a small group of patients $(\mathrm{n}=161)$. A recent study involving 100 patients with familial hypercholesterolaemia and normal glucose tolerance, treated with 10 to $40 \mathrm{mg}$ /day of atorvastatin, showed a significant reduction in microalbuminuria and a significant increase in $\mathrm{CrCl}^{43}$ In addition, to date no other statin trial has included the measurement of proteinuria. Undoubtedly, the results of the GREACE trial (fall in SCr) together with the rosuvastatin findings (complication mentioned in the rosuvastatin data sheet) will lead to a greater awareness about renal function, proteinuria, and statins.

\section{CONCLUSIONS}

In dyslipidaemic patients with CHD who have normal baseline renal function, there is a decline in $\mathrm{CrCl}$ over time, which further increases the risk for clinical events related to arteriosclerotic cardiovascular disease.

In contrast, patients on longterm aggressive statin treatment experience a significant increase in $\mathrm{CrCl}$, which contributes to the reduction of risk for clinical events. Prevention of an additional CHD risk factor, such as renal insufficiency, might prove to be beneficial for patients with established CHD. Renal and coronary artery disease may progress in parallel. Similar treatments (for example, statins) may be beneficial to both the heart and kidneys. 


\section{Take home messages}

- Patients with dyslipidaemia and coronary heart disease (CHD) who have normal baseline renal function show a decline in creatinine clearance over time, which further increases the risk for CHD related clinical events

- Longterm aggressive statin treatment significantly increases creatinine clearance, contributing to the reduction of risk for clinical events

- This beneficial effect is greatest in those with early renal dysfunction

- Prevention of an additional CHD risk factor, such as renal insufficiency, might be beneficial for patients with established CHD

- Statins may be beneficial to both the heart and the kidneys

\section{Authors' affiliations}

V G Athyros, A N Pehlivanidis, V I Bouloukos, Atherosclerosis Unit, Aristotelian University, Hippocration Hospital, 49 Konstantinoupoleos St, Thessaloniki, 546 42, Greece

A A Papageorgiou, Second Propedeutic Department of Internal Medicine, Aristotelian University

D P Mikhailidis, Department of Clinical Biochemistry, Royal Free Hospital, Royal Free and University College Medical School, Pond Street, London NW3 2QG, UK

A N Symeonidis, Greek Society of General Practitioners, 21 N. Koudourioti St, Thessaloniki, 546 25, Greece

M Elisaf, Department of Internal Medicine, Medical School, University of loannina, 451 10, Greece

For the GREACE Study Collaborative Group.

\section{REFERENCES}

1 Schaeffner ES, Kurth T, Curhan GC, et al. Cholesterol and the risk of renal dysfunction in apparently healthy men. J Am Soc Nephrol 2003;14:2084-91.

2 Kasiske BL, O'Donnell MP, Cleary MP, et al. Treatment of hyperlipidemia reduces glomerular injury in obese Zucker rats. Kidney Int 1988;33:667-72.

3 Kasiske BL, O'Donnell MP, Garvis WJ, et al. Pharmacologic treatment of hyperlipidemia reduces glomerular injury in rat $5 / 6$ nephrectomy model of chronic renal failure. Circ Res 1988;62:367-74.

4 Harris KPG, Pukerson ML, Yates J, et al. Lovastatin ameliorates the development of glomerulosclerosis and uremia in experimental nephrotic syndrome. Am J Kidney Dis 1990;15:16-23.

5 Fried LF, Orchard TJ, Kasiske BL, for the Lipids and Renal Disease Progression Meta-Analysis Study Group. Effect of lipid reduction on the progression of renal disease: a meta-analysis. Kidney Int 2001;59:260-5.

6 Mänttäri M, Tiula E, Alikoski T, et al. Effects of hypertension and dyslipidemia on the decline in renal function. Hypertension 1995;26:670-5.

7 Elisaf $M$. Effects of fibrates on serum metabolic parameters. Curr Med Res Opin 2002;18:269-76.

8 Heart Protection Study Collaborative Group. MRC/BHF heart protection study of cholesterol-lowering with simvastatin in 5963 people with diabetes: a randomised placebo-controlled trial. Lancet 2003;361:2005-16.

9 Athyros VG, Papageorgiou AA, Mercouris BR, et al. Treatment with atorvastatin to the national cholesterol educational program goals versus usual care in secondary coronary heart disease prevention. The Greek atorvastatin and coronary-heart-disease evaluation (GREACE) study. Curr Med Res Opin 2002; 18:220-8

10 Mikhailidis DP, Wierzbicki AS. Editorial: the Greek atorvastatin and coronary-heart disease evaluation (GREACE) study. Curr Med Res Opin 2002:18:215-19.

11 National Cholesterol Education Program. Second report of the expert pane on detection, evaluation, and treatment of high blood cholesterol in adults (adult treatment panel II). Circulation 1994;89:1333-445.

12 National Cholesterol Education Program. The third report of the national cholesterol education program (NCEP) expert panel on detection, evaluation, and treatment of high blood cholesterol in adults (adult treatment panel III). JAMA 2001;285:2486-97.

13 Athyros VG, Mikhailidis DP, Papageorgiou AA, et al. Attaining United Kingdom-European Atherosclerosis Society low-density lipoprotein cholesterol guideline target values in the Greek atorvastatin and coronary-heart-disease evaluation (GREACE) study. Curr Med Res Opin 2002;18:499-502.

14 Cockroft DW, Gault MH. Prediction of creatinine clearance from serum creatinine. Nephron 1976;16:31-41.

$15 \mathrm{~K} / \mathrm{DOQ}$ clinical practice guidelines for chronic kidney disease: evaluation, classification, and stratification. Kidney disease outcome quality initiative. Am J Kidney Dis 2002;39:S1-246.

16 Dahlof B, Devereux RB, Kieldsen SE, et al. The LIFE study group. Cardiovascular morbidity and mortality in the Losartan intervention for endpoint reduction in hypertension study (LIFE): a randomised trial against atenolol. Lancet 2002;359:995-1003

17 Yamashita T, Kawahsim S, Miwa Y, et al. A 3-hydroxy-3-methylglutaryl coenzyme A reductase inhibitor reduces hypertensive nephrosclerosis in strokeprone spontaneously hypertensive rats. J Hypertens 2002;20:2465-73.

18 Davignon J, Laaksonen R. Low-density lipoprotein-independent effects of statins. Curr Opin Lipidol 1999;10:543-59.

19 O' Driscoll G, Green D, Taylor RR. Simvastatin, and HMG-coenzyme A reductase inhibitor improves endothelial function within 1 month. Circulation 1997;95:1126-231.

20 Huggins GS, Pasternak RC, Alpert NM, et al. Effects of short-term treatment of hyperlipidemia on coronary vasolidator function and myocardial perfusion in regions having substantial impairment of baseline dilator reverse. Circulation 1998;98:1291-6

21 Tsiara S, Elisaf M, Mikhailidis DP. Early vascular benefits of statin therapy. Curr Med Res Opin 2003:19:540-56

22 Gin H, Rigalleau V, Aparicio M. Lipids, protein intake, and diabetic nephropathy. Diabetes Metab 2000;26(suppl 4):45-53.

23 Guijarro C, Kasiske BL, Kim Y, et al. Early glomerular changes in rats with dietary-induced hypercholesterolemia. Am J Kidney Dis 1995;26:152-61.

24 Keane WF, Kasiske BL, O'Donnell MP. Hyperlipidemia and the progression of renal disease. Am J Clin Nutr 1988;47:157-60.

25 Diamond JR, Karnovsky MJ. Focal and segmental glomerulosclerosis: analogies to atherosclerosis. Kidney Int 1988;33:917-24.

26 Moorhead JF. Lipids and progressive renal disease. Kidney Int 1991;39:35-40.

27 O'Donnell MP, Kasiske BL, Kim Y, et al. Lovastatin retards the progression of established glomerular disease in obese Zucker rats. Am J Kidney Dis 1993:22:83-9.

28 Yokota N, O'Donnell M, Daniels $F$, et al. Protective effect of HMG-CoA reductase inhibitor on experimental renal ischemia-reperfusion injury. Am J Nephrol 2003;23:13-17.

29 Massy ZA, Kim Y, Guijarro C, et al. Low-density lipoprotein-induced expression of interleukin-6, a marker of human mesangial cell inflammation: effects of oxidation and modulation by lovastatin. Biochem Biophys Res Commun 2000;267:536-40.

30 Joyce $M$, Kelly $C$, Winter $D$, et al. Pravastatin, a 3-hydroxy-3-methylglutaryl coenzyme $A$ reductase inhibitor, attenuates renal injury in an experimental model of ischemia-reperfusion. J Surg Res 2001;101:79-84.

31 Keane WF, Kasiske BL, O'Donnell MP. The role of lipids in progressive glomerular disease. Adv Exp Med Biol 1987;223:81-87.

32 Miyata J, Takebayashi S. Effect of hyperlipidaemia on glomerular sclerosis in uninephrectomised rats. Acta Pathol Jpn 1987;37:1433-9.

33 Heart Protection Study Collaborative Group. MRC/BHF heart protection study of cholesterol lowering with simvastatin in 20536 high-risk individuals: a randomized placebo-controlled trial. Lancet 2002;360:7-22.

34 Elisaf $M$, Mikhailidis DP. Statins and renal function. Angiology 2002;53:493-502.

35 Athyros VG, Papageorgiou AA, Elisaf $M$, et al. Statins and renal function in patients with diabetes mellitus. Curr Med Res Opin 2003;19:615-17.

36 Kakafika $A$, Liamis $G$, Elisaf $M$, et al. Effect of atorvastatin on serum creatinine levels. Curr Med Res Opin 2001;17:230-1.

37 Youssef $F$, Seifalian AM, Jagroop IA, et al. The early effect of lipid-lowering treatment on carotid and femoral intima media thickness (IMT). Eur J Vasc Endovasc Surg 2002;23:358-64.

38 Youssef F, Gupta P, Seifalian AM, et al. The effect of short-term treatment with simvastatin on renal function in patients with peripheral arterial disease. Angiology [ln press.]

39 Kaplan RC, Heckbert SR, Furberg CD, et al. Predictors of subsequent coronary events, stroke, and death among survivors of first hospitalized myocardial infarction. J Clin Epidemiol 2002;55:654-64.

40 Bianchi S, Bigazzi R, Caiazza A, et al. A controlled, prospective study of the effects of atorvastatin on proteinuria and progression of kidney disease. Am J Kidney Dis 2003;41:565-70.

41 Athyros VG, Papageorgiou AA, Symeonidis AN, et al. Early benefit from structured care with atorvastatin in patients with coronary heart disease and diabetes mellitus. A subgroup analysis of the Greek atorvastatin and coronary-heart-disease evaluation (GREACE) study. Angiology 2003;54:679-90

42 Velussi M. Long-term (18-month) efficacy of atorvastatin therapy in type 2 diabetics at cardiovascular risk. Nutr Metab Cardiovasc Dis 2002;12:29-35.

43 Sinzinger $\mathrm{H}$, Kritz $\mathrm{H}$, Furberg $\mathrm{CD}$. Atorvastatin reduces microallbuminuria in patients with familial hypercholesterolemia and normal glucose tolerance. Med Sci Monit 2003;9:88-92. 